\title{
The Prevalence and Demographic Risk Factors for Latent Tuberculosis Infection (LTBI) Among Healthcare Workers in Semarang, Indonesia
}

This article was published in the following Dove Press journal: Journal of Multidisciplinary Healthcare

\author{
Meira Erawati \\ Megah Andriany \\ Department of Nursing, Faculty of \\ Medicine, Universitas Diponegoro, \\ Semarang, Indonesia
}

Correspondence: Meira Erawati Department of Nursing, Faculty of Medicine, Universitas Diponegoro, Jl. Prof. Soedarto, SH., Tembalang, Semarang, Central Java 1269 , Indonesia Tel +6281617507416

Email mei_ra07@fk.undip.ac.id
Purpose: To determine the prevalence and demographic risk factors for latent tuberculosis infection (LTBI) among healthcare workers in Semarang, Indonesia.

Methods: A cross-sectional study involving 195 healthcare workers from 34 primary health centers was conducted from August to October 2019. The relationship between independent variables and dependent variables was analyzed using a multivariable logistic regression analysis. Results: The prevalence of LTBI among healthcare workers in this study was $23.6 \%$. Comorbidities were the only risk factor for LTBI identified among other risk factors $(\mathrm{OR}=3.39$, 95\% CI: 0.99-11.62, $p=0.04)$. Other demographic factors such as age $(\mathrm{OR}=0.93$, 95\% CI: $0.45-1.92, p=0.839)$, gender $(\mathrm{OR}=0.79,95 \% \mathrm{CI}: 0.23-2.72, p=0.708$, smoking habits $(\mathrm{OR}=2.54,95 \% \mathrm{CI}: 0.52-12.38, p=0.247)$, and length of work $(\mathrm{OR}=1.43$, 95\% CI: $0.70-2.91, p=0.331)$ were not significant risk factors for LTBI.

Conclusion: Healthcare workers suffering from comorbidity have a high risk for tuberculosis infection, and should not work in areas where they would be exposed to patients with tuberculosis. Healthcare workers need to apply occupational safety standards during contact with TB patients or specimens to minimize the disease transmission.

Keywords: demographic risk factors, healthcare workers, LTBI

\section{Introduction}

The World Health Organization (WHO) estimated that the population of people with tuberculosis (TB) in 2018 would reach 10 milc t3lion (within the range of 9.0-11.1 million). Indonesia ranks third for the incidence of TB in the world after India and China. ${ }^{1}$ In Semarang city, the newly identified cases of TB in 2017 reached

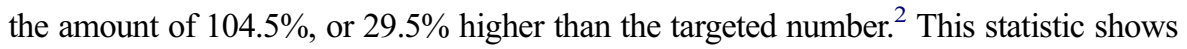
the success of government programs in identifying new cases, but at the same time, is worrying as it shows high cases in the community. Considering the high incidence of TB in Indonesia, TB management should be given a priority. One of the prevention programs promoted in Indonesia is a treatment that is directly observed or known as Directly Observed Treatment, Short-course (DOTS). ${ }^{3}$

TB infection is caused by Mycobacterium tuberculosis (M. tuberculosis), which can spread easily from a patient to those people around him through the air when the patient coughs or talks. Splashes of saliva from the patient containing M. tuberculosis can be easily inhaled and enter the lungs, a favorite place for the bacteria as they are rich in oxygen. In the lungs, the bacteria find new places to live and multiply. When the host immune system is weak, the bacteria will multiply and cause new infections. ${ }^{4}$ 
Healthcare workers are at a high risk of LTBI and active TB disease due to occupational exposure from patients. ${ }^{5}$ A study in Indonesia reported a significant relationship between interferon-gamma release assay (IGRA) tests and workplace, as evidenced by the results of positive IGRA on 37 (37.4\%) hospital healthcare workers involved in the study. ${ }^{6}$

Increasing age and length of work (indicating amount of exposure) are related to high incidence of LTBI among healthcare workers. Research shows that the incidence of LTBI among healthcare workers increases 1.04 times with increasing age every year, ${ }^{7,8}$ and 1.5 to 2.4 times with work length of more than one year. ${ }^{8,9}$ After three years, the prevalence is three times higher. ${ }^{10}$ Working on the ward and procedures directly related to patients (such as sputum collection, autopsy), as well as a history of contact with TB patients, are occupational risk factors for LTBI. Previous studies reported the prevalence of TB among nurses. Groups of nurses with high frequency of contacts with patients are potentially affected. The prevalence of LTBI among nurses ranged from $43 \%$ to $87 \%$. This rate indicates that nurses have a higher risk for LTBI than other healthcare professionals. ${ }^{8,11}$

A majority of healthcare workers are exposed to M. tuberculosis without clinical symptoms or radiologically active tuberculosis. Nevertheless, many showed positive results on the examination of the tuberculin skin test (TST). This condition is known as latent tuberculosis infection. Healthcare workers with latent tuberculosis status have no risk of transmitting the infection to other people; instead, they have a risk of becoming active TB sufferers when their immune system declines. ${ }^{12}$

Previous studies have shown different risk factors for LTBI among healthcare workers in a number of healthcare centers. ${ }^{13-15}$ Risk factors for $\mathrm{TB}$ in healthcare workers throughout the world increase the risk of being infected with the disease. These factors include age, gender (male), smoking habits, length of work, professional groups (doctors and nurses, working with patients), late diagnosis and misdiagnosis in patients, no suspected clinical signs, and the lack or insufficiency of personal protective equipment and preventive measures. ${ }^{16-21}$

Unhealthy habits, such as alcohol consumption, are also a risk factor for TB infection. ${ }^{22}$ It is because alcohol can damage the immune system, resulting in decreased body's ability to resist infection, contribute to the damage of the organs associated with alcohol consumption, and inhibits recovery from tissue injury. ${ }^{23}$ In addition, nutritional status is also closely related to TB infection. Diabetes provides the highest risk of TB in overweight and obese adults. ${ }^{24}$
Healthcare workers have a high risk of TB infection when they provide services to their patients. However, data on how many healthcare workers suffering from LTBI, especially in Semarang city, are not yet known. It is because healthcare workers suffering from LTBI do not show any symptoms of the disease, and, therefore, specific examinations are required. For this reason, LTBI in healthcare workers often goes unnoticed and is at risk of becoming active TB.

Healthcare workers are one of the vulnerable groups to TB infection from patients. On the contrary, healthcare workers who suffer from active TB and provide services to patients can also be agents of infection transmission. Such a condition needs to be given special attention, mainly if the healthcare worker provides services to children. It is because children, especially under the age of six, are vulnerable groups to TB infection from healthcare workers, for example, when the children receive immunizations. ${ }^{25}$

LTBI sufferers who are confirmed positive by IGRA and TST are programmed to have drug regimen therapy. There are some alternatives of drug regimen for LTBI, including INH consumed once a day for six months, INH consumed once a day for nine months, a combination of INH and Rifampicin consumed once a day for 3-4 months, and a combination of Rifapentin and INH consumed once a week for three months. ${ }^{26}$

Therefore, it is crucial to conduct a study to investigate the prevalence and risk factors for LTBI among healthcare workers in Semarang city, so that it can be used as a basis for planning future programs of TB control.

\section{Materials and Methods Research Design}

A cross-sectional study was conducted from August to October 2019, involving 200 healthcare workers who provided direct or indirect services to TB patients. These healthcare workers were recruited from 34 primary health centers in Semarang city, including doctors, nurses, health analysts, pharmacists, epidemiologists, health surveyors, administrative staffs, and cleaners. Non-systematic random sampling was used to recruit the respondents. Demographic information about the respondents was collected using a questionnaire. The respondents signed informed consent after they expressed their agreement to participate in the study. Ethical approval was received from the research ethics committee of Department of Nursing, Faculty of Medicine, Diponegoro University (No. 42/EC/KEPK/D.Kep.VI/2019, dated June 18,2019). This study was conducted in concordance with the Declaration of Helsinski. 


\section{Sample Collection}

Four (4) $\mathrm{mL}$ of blood was drawn from the vein of each respondent and put into four reservoirs; each consisted of $1 \mathrm{~mL}$ of blood (following the manufacturer's operational instructions). All blood samples from the respondents were sent to Kimia Farma clinical laboratory for further analysis.

\section{Laboratory Investigation}

This study used the IGRA test of QuantiFERON-TB type to analyze the blood samples. The test was done based on the Qiagen manufacturer's recommendation. In brief, the test began with a process of incubating blood samples at $37^{\circ} \mathrm{C}$ for one night. Next, the tubes were centrifuged at $2.500 \mathrm{rpm}$ for 15 mins. The samples were then analyzed and calculated based on the QFT-GIT analysis software (version 2.62). A sample was considered positive if the TB control value minus with nil was $>0.35 \mathrm{IU} / \mathrm{mL}$ and $>25 \%$ of the nil value.

\section{Statistical Analysis}

Data were entered into IBM SPSS software version 20. Categorical variables were presented in frequency and percentage. The relationship between independent variables and dependent variables was analyzed using a multivariable logistic regression analysis. A $p$-value of $<0.05$ was considered statistically significant. The odds ratio analysis was used to estimate the magnitude of the risk factors of the disease.

\section{Results}

The Department of Health of Semarang city oversees 37 primary health centers (PHC) in its area. Hence, data in this study were collected from 34 PHCs throughout the city. Three PHCs were unable to participate in the study as they did confirm their availability to participate until the study was completed.

A total of 200 healthcare workers participated in this study; however, five (3\%) of them were excluded as they had indeterminate QuantiFERON-TB results. At last, this study involved 195 (97\%) health care workers who met the criteria. The process of determining the respondents is presented in Figure 1.

The participation of healthcare workers in each PHC is shown in Figure 2. The number of the respondents in each PHC ranged from 3 to 10. A majority of respondents came from Poncol PHC (10 respondents), and the least came from Bugangan PHC (3 respondents).

The results of this study indicated that the mean age of respondents was 36.02 and the majority were women

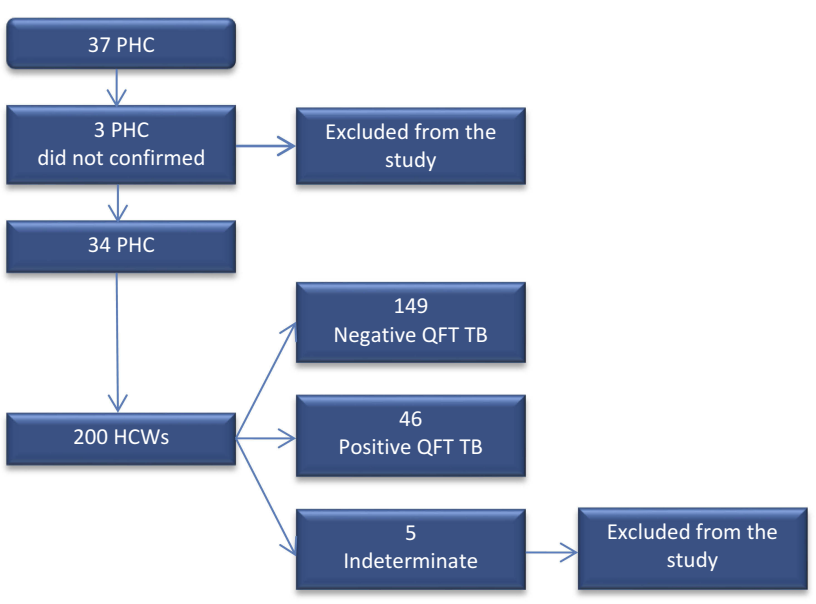

Figure I Flowchart of the studied population.

$(\mathrm{n}=158,81 \%)$. Most respondents worked as nurses $(\mathrm{n}=$ $82.42 \%)$, and $23(12 \%)$ respondents were smokers. There were $12(6 \%)$ respondents with illness; 10 of them suffered from diabetes mellitus (DM), and the other two suffered from hepatitis. A total of 104 (53\%) respondents had worked in the PHC for more than 10 years. Forty-six (23\%) out of 195 respondents showed positive IGRA, indicating the presence of LTBI. The characteristics of the respondents are presented in Table 1.

The odds ratio analysis showed that healthcare workers with current illness were more susceptible to LTBI (OR=3.39, 95\% CI: $0.99-11.62, p=0.04$ ), and midwives are at higher risk for LTBI than other healthcare professions, although the risk is not statistically significant. (OR=3.2, 95\% CI: $0.48-21.29, p=0.230)$. Other demographic factors such as age $(\mathrm{OR}=0.93,95 \% \mathrm{CI}$ : $0.45-1.92, p=0.839)$, gender ( $\mathrm{OR}=79,95 \% \mathrm{CI}: 0.23-2.72$, $p=0.708)$, smoking habits $(\mathrm{OR}=2.54,95 \% \mathrm{CI}: 0.52-12.38$, $p=0.247$ ), and length of work ( $\mathrm{OR}=1.43,95 \%$ CI: $0.70-2.91$, $p=0.331$ ) were not significant risk factors for LTBI (see Table 2 )

\section{Discussion}

Indonesia, officially the Republic of Indonesia, is a country in Southeast Asia, between the Indian and Pacific oceans. It is the world's largest island country, with more than seventeen thousand islands, and at 1,904,569 square kilometres, the 14th largest by land area and 7th in the combined sea and land area. The description of population distribution in Indonesia can be seen in Figure 3.

Considering the structure of population distribution, as shown in Figure 3, it is not surprising that some areas in Indonesia have a very high population density that becomes one of the risks of TB development. There is 


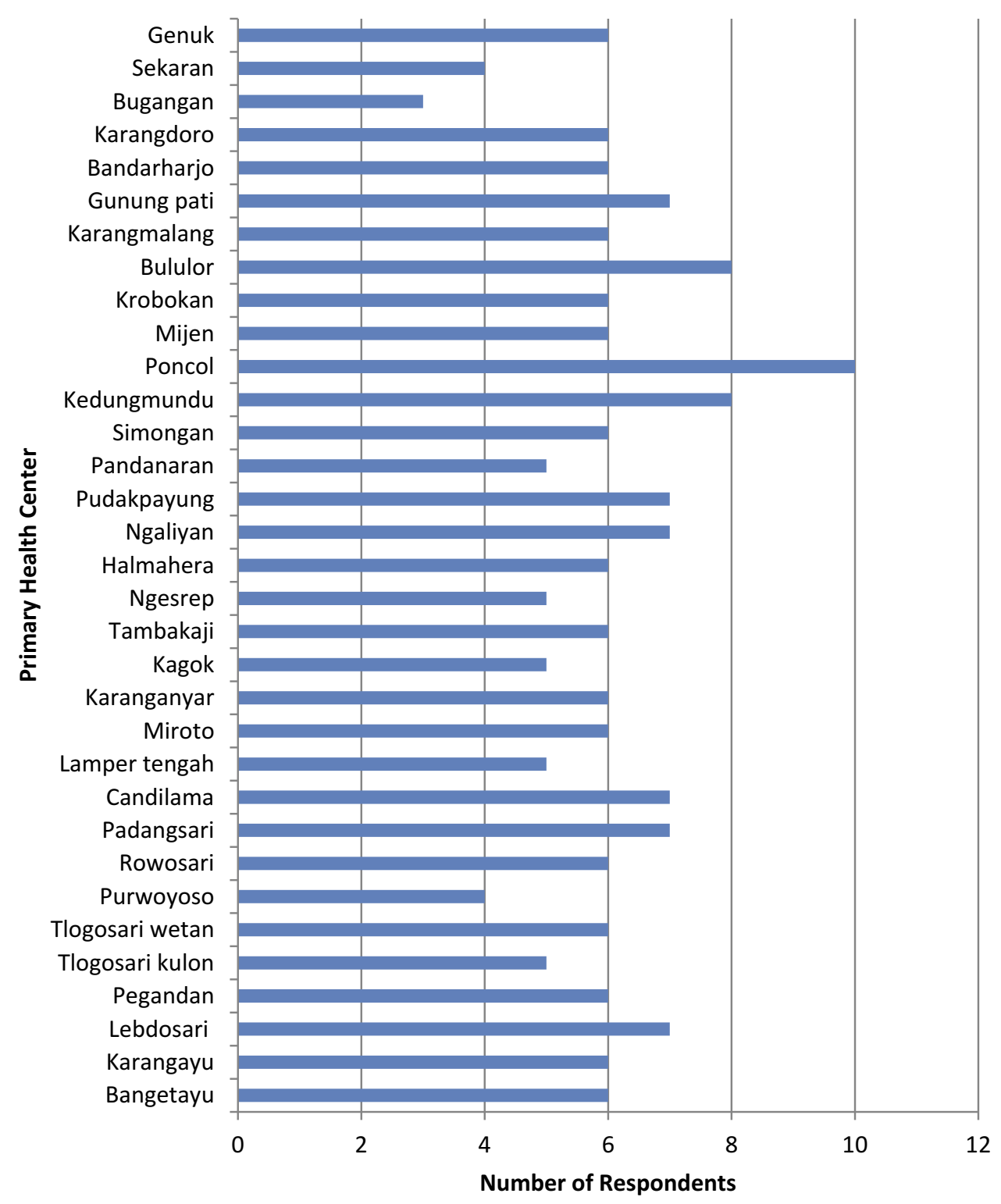

Figure 2 Distribution of healthcare workers in each PHC participating in the study.

evidence that Indonesia is the country with the highest incidence of TB compared to other neighboring countries in Southeast Asia, which border directly with Indonesia. Data from the WHO in 2018 showed that the incidence of TB in Indonesia was 316 people per 100,000 population. This statistic is much higher when compared to Malaysia or Brunei Darussalam with a TB incidence of 92 and 68 people, respectively, per 100,000 population in the same year. Singapore has the lowest rate of TB incidence of 47 people per 100,000 population. ${ }^{28}$

Indonesia consists of 34 provinces. One of the most populous islands is Java that comprised of 6 provinces, one of which is Central Java. Data show that Central Java province ranks third as the province with the highest incidence of TB in
Java Island after West Java and East Java provinces. As the capital city of Central Java province, Semarang city also ranks third in the incidence of TB within the province. The population density in Semarang ranges from 1277 to 12,307 people/ $\mathrm{km}^{2}$, with an average room temperature above $31^{\circ} \mathrm{C}$ in the entire region. $^{29}$

Areas with high population density and high temperatures are hazardous for the presence and development of TB disease. ${ }^{30}$ The description of areas in Semarang city with a high incidence of TB can be seen in Figure 4.

Healthcare workers can have a high risk of TB transmission in their workplace. Therefore, screening and exploration of the determinants of LTBI among healthcare workers is a crucial step to reduce the incidence. 
Table I Characteristics of Respondents

\begin{tabular}{|l|l|}
\hline Variable & No. (\%) \\
\hline $\begin{array}{l}\text { Age } \\
<40 \text { years old }\end{array}$ & $126(64.62)$ \\
$\geq 40$ years old & $69(35.38)$ \\
\hline Gender & \\
Male & $37(18.97)$ \\
Female & $158(81.03)$ \\
\hline Occupation & \\
Nurses & $82(42.05)$ \\
Laboratory technicians & $45(23.07)$ \\
Doctors & $28(14.36)$ \\
Epidemiologists & $6(3.08)$ \\
Midwives & $5(2.56)$ \\
Health surveyors & $7(3.58)$ \\
Miscellaneous & $22(11.28)$ \\
\hline Cigarette smokers & \\
No & $172(88.2)$ \\
Yes & $23(11.8)$ \\
\hline Current illness & \\
No & $183(93.85)$ \\
Yes* & $12(6.15)$ \\
\hline Length of work & \\
$<10$ years & $104(53.33)$ \\
\hline IGRA test & $149(76.4 I)$ \\
Negative & $46(23.59)$ \\
\hline Positive & $97.67)$ \\
\hline
\end{tabular}

Note: *Current illnesses of respondents includes DM (10 people) and hepatitis (2 people).

Furthermore, based on the resulted data, more precise and targeted TB risk planning and management can be prepared. In this study, the prevalence of LTBI among healthcare workers was $23.6 \%$. It is higher than that in Duhok (12\% of 395) as reported by Almufty. ${ }^{32}$ This difference might be due to different characteristics of the respondents between the two studies. In this study, the respondents were healthcare workers who provided services to $\mathrm{TB}$ patients, while the respondents in Duhok were randomly selected from all healthcare workers. High frequency and intensity of interaction with TB patients increases the risk of TB transmission from patients to healthcare workers. However, other research involving respondents with similar demographic and geographical characteristics as Duhok also reported a high prevalence of TB $(27.8 \%) .{ }^{33}$ This result shows that demographic data of healthcare workers are not the only risk factors determining the infection.
The laboratory analysis in this study was carried out using the IGRA test to determine whether the respondents had LTBI or not. Positive results indicated that they had LTBI. In contrast, negative results indicated that respondents were healthy. Studies in neighboring countries proved that the IGRA test showed better sensitivity and specificity than the TST examination to establish a diagnosis of LTBI. A study conducted in Bandung, Indonesia, also reported a high prevalence of LTBI among healthcare workers who were examined using IGRA and TST tests. From the study, it was revealed that among 84 respondents, the prevalence of LTBI was $51.2 \%$ (IGRA) and $29.8 \%$ (TST) with a sufficient kappa value $(\kappa=0.34) .{ }^{34} \mathrm{WHO}$ recommends the use of TST and IGRA tests to investigate LTBI in high and middle-income countries with low TB incidence (the incidence is less than 100 per 100,000 populations). Meanwhile, for low and middle-income countries with high TB incidence, the IGRA test should not replace the use of TST test. ${ }^{35}$ In addition to being more sensitive than the TST, the IGRA test results are least affected and even not affected by BCG immunization. Therefore, the IGRA test is recommended to be used in groups of people who extensively receive BCG immunization. ${ }^{36}$ Furthermore, based on the results of previous studies, the IGRA test also shows more consistent results than the TST for screening the LTBI in immunocompromised patients, such as HIV. ${ }^{37}$

Age is associated with a relatively high TB prevalence. Most of the respondents in this study were aged $<40$ years amounted to $129(66.15 \%)$ out of 195 . Healthcare workers older than 40 years have a higher risk of TB infection than the younger ones. Currently, the highest incidence globally occurs at the age of 45-55 (productive age). Nonetheless, in Western Pacific Regions, Eastern Mediterranean, and Southeast Asia, the incidence of TB is quite high in the elderly, and the peak occurs in older adults aged $\geq 65$ years old. $^{3}$ In old age, the immune system has passed through various evolutionary processes, and its ability is decreasing. ${ }^{38}$ One of the indicators is the changes in the characteristics of the $\mathrm{T}$ cells that are very instrumental in resisting attacks from exogenous microorganisms such as viruses and bacteria. ${ }^{39}$ This situation will affect increasing susceptibility to various diseases, especially infectious diseases, including TB infections.

The length of time of exposure and contact with patients can cause an increased risk of infection. High intensity and duration of exposure to infectious agents increase the risk of healthcare workers to be infected with TB. In this study, 104 $(53.33 \%)$ respondents had worked for more than ten years. In the health sector, the prevalence of LTBI increases with the 
Table 2 Distribution of Respondents Based on TB Risk Factors and IGRA Test

\begin{tabular}{|c|c|c|c|c|c|c|c|}
\hline \multirow[t]{3}{*}{ Risk Factors } & \multicolumn{4}{|c|}{ IGRA Test } & \multirow[t]{3}{*}{ Total (\%) } & \multirow[t]{3}{*}{ Odds Ratio (95\% Cl) } & \multirow[t]{3}{*}{$P$-value } \\
\hline & \multicolumn{2}{|c|}{ Positive $(n=46)$} & \multicolumn{2}{|c|}{ Negative $(n=149)$} & & & \\
\hline & $\mathbf{n}$ & $\%$ & $\mathbf{n}$ & $\%$ & & & \\
\hline \multicolumn{8}{|l|}{ Age (year) } \\
\hline$<40$ (ref) & 29 & 63.04 & 97 & 65.10 & $126(64.62)$ & $0.93(0.45-1.92)$ & 0.839 \\
\hline$\geq 40$ & 17 & 36.96 & 52 & 34.90 & $69(35.38)$ & & \\
\hline \multicolumn{8}{|l|}{ Gender } \\
\hline Male (ref) & 10 & 21.74 & 27 & 18.12 & $37(18.97)$ & 0.79 & \\
\hline Female & 36 & 78.26 & 122 & 81.88 & I58 (81.03) & $(0.23-2.72)$ & 0.708 \\
\hline \multicolumn{8}{|l|}{ Occupation } \\
\hline Nurses (ref) & 17 & 36.96 & 65 & 43.62 & $82(42.05)$ & & \\
\hline Laboratory Technicians & 13 & 28.26 & 32 & 21.48 & $45(23.07)$ & $1.65(0.69-3.95)$ & 0.259 \\
\hline Doctors & 5 & 10.87 & 23 & 15.44 & $28(14.36)$ & $1.03(0.35-3.0)$ & 0.953 \\
\hline Epidemiologists & I & 2.17 & 5 & 3.36 & $6(3.08)$ & $0.93(0.10-8.73)$ & 0.952 \\
\hline Midwives & 2 & 4.35 & 3 & 2.01 & $5(2.56)$ & $3.20(0.48-21.29)$ & 0.230 \\
\hline Health surveyors & 0 & 0 & 7 & 3.36 & $7(3.58)$ & $0(0)$ & 0.999 \\
\hline Miscellaneous & 8 & 17.4 & 14 & 10.74 & $22(11.28)$ & $1.82(0.60-5.50)$ & 0.289 \\
\hline \multicolumn{8}{|l|}{ Cigarette smokers } \\
\hline No (ref) & 40 & 86.96 & 132 & 88.60 & I72 (9I.8) & 2.54 & 0.247 \\
\hline Yes & 6 & 13.03 & 17 & 11.40 & $23(8.2)$ & $(0.52-12.38)$ & \\
\hline \multicolumn{8}{|l|}{ Current illness } \\
\hline No (ref) & 40 & 86.96 & 143 & 95.97 & I83 (93.85) & 3.39 & 0.04 \\
\hline Yes & 6 & 13.03 & 6 & 4.03 & $12(6.15)$ & $(0.99-11.62)$ & \\
\hline \multicolumn{8}{|l|}{ Length of work } \\
\hline$<10$ years (ref) & 17 & 36.96 & 74 & 49.66 & 91 (46.67) & 1.43 & 0.331 \\
\hline$\geq 10$ years & 29 & 63.04 & 75 & 50.34 & $104(53.33)$ & $(0.70-2.91)$ & \\
\hline
\end{tabular}

Note: The data analysis was performed using a multivariable logistic regression analysis.

length of work ( $>20$ years) and the increasing age ( $>55$ years old). ${ }^{40}$ The incidence in younger ages in this study is different from most published literature, stating that the risk of LTBI is directly related to the increasing age. ${ }^{16,41}$ The correlation between increasing age and risk for LTBI is related to prolonged exposure to $M$. tuberculosis infection. The reason why the risk for LTBI is high in people aged 30 to 39 is not clearly explained in the study. It might be because the number of young respondents in the study was higher than that of elderly respondents. Further research is needed to have a better understanding of the relationship between LTBI and age. The analysis of the study is not congruent with the results of the present study, in which healthcare workers aged less than 40 and older did not show significant differences in LTBI (OR $=0.93,95 \%$ CI: $0.45-1.92, p=0.839)$. In addition, healthcare workers working for more than ten years and less did not show a significant difference in the risk of LTBI
(OR=1.43, 95\% CI: 0.70-2.91, $p=0.331)$. This may happen as people are accustomed to a healthy lifestyle, exercise, healthy food consumption, positive thinking, and happiness so that they have an good immune system and are not susceptible to infectious diseases. ${ }^{42,43}$

A majority of respondents were females amounting to $158(81.03 \%)$. The risk of LTBI in men and women did not differ significantly in this study $(\mathrm{OR}=0.79,95 \% \mathrm{CI}$ : $0.23-2.72, p=0.708)$. It is in line with a previous study conducted in China that reported no differences in the incidence of TB between men and women $(\mathrm{OR}=0.83, \mathrm{CI}$ : $0.52-1.35, p=0.457) .{ }^{44}$ Nevertheless, this result is in contrast with a systematic review by Horton, stating that the prevalence of $\mathrm{TB}$ is significantly higher in men than women, especially in low and middle-income countries. Men are less persistent in seeking or accessing TB care. It was evident that men have a high prevalence ratio of 2.21 


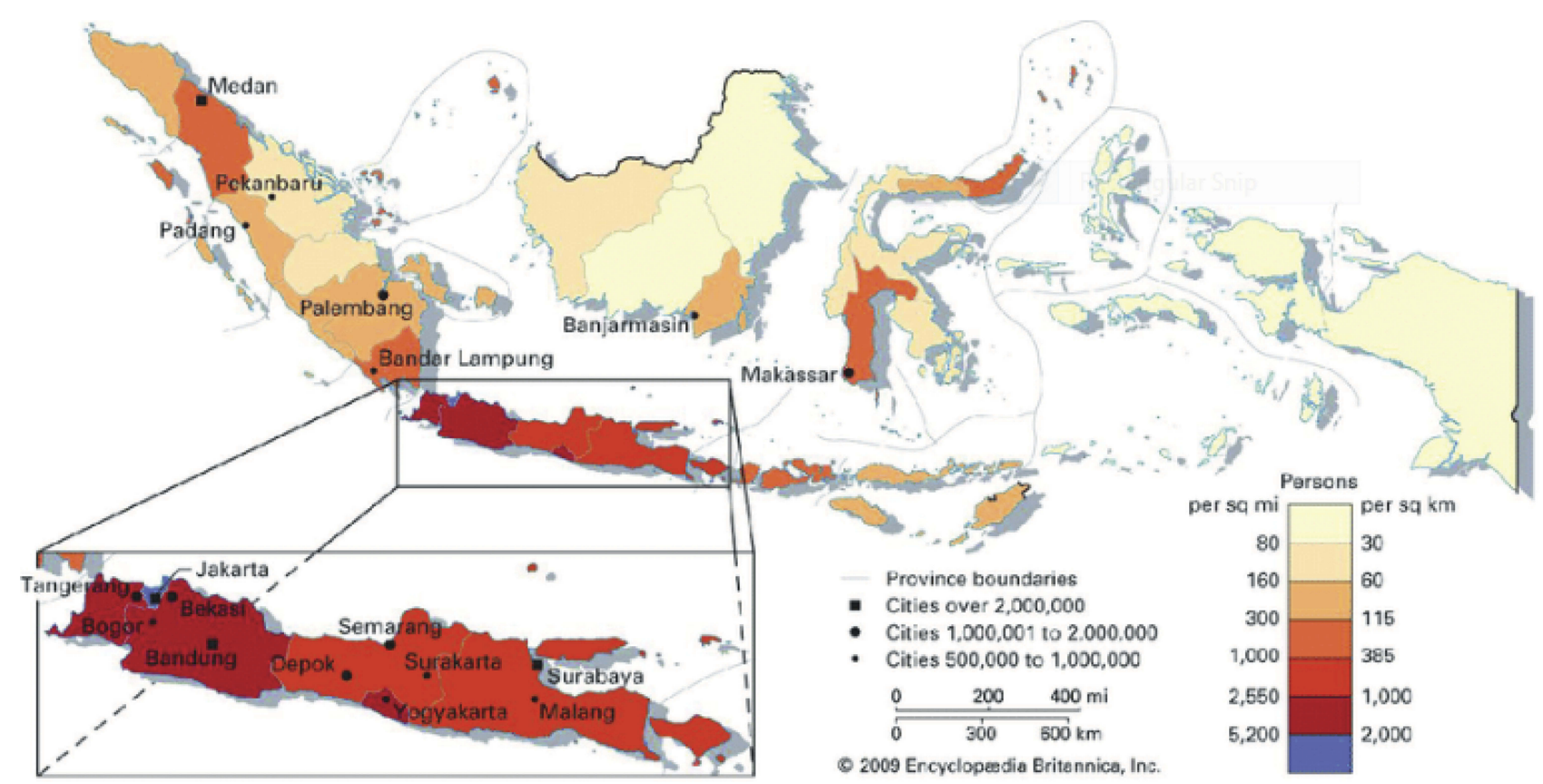

Figure 3 The description of population density in Indonesia.

Notes: Reproduced from Wolters OW, Leinbach TR, Legge JD, McDivitt JF, Adam AW, Mohamad GS. Indonesia: population density. In: Encyclopædia Britannica. Chicago, IL: Encyclopædia Britannica, Inc.; 2020. By courtesy of Encyclopædia Britannica, Inc., copyright 2009; used with permission. ${ }^{27}$

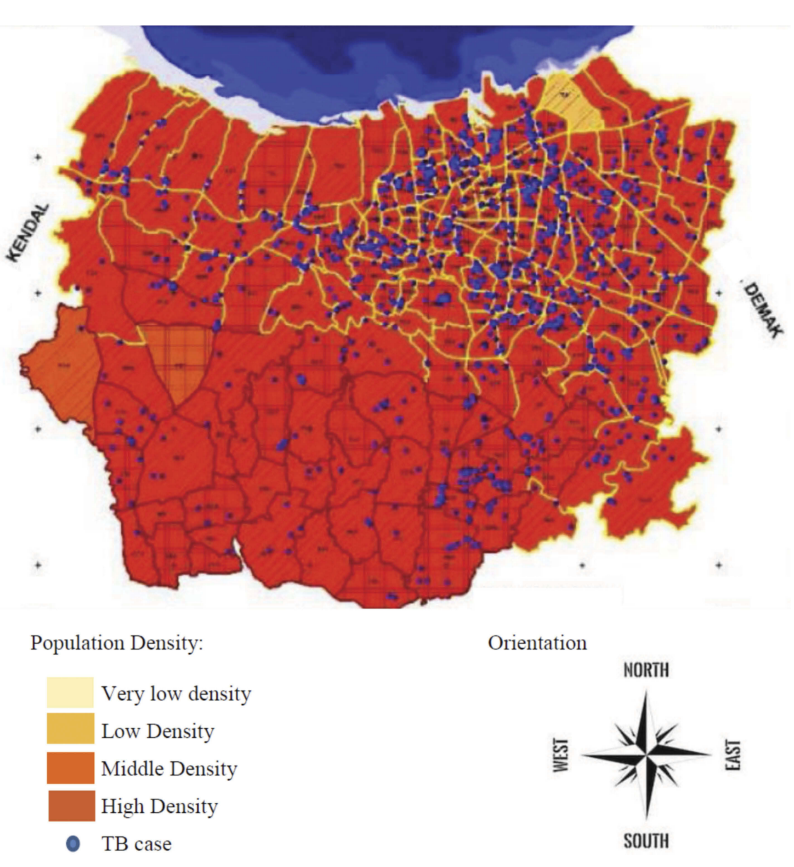

Figure 4 Distribution of TB in Semarang city based on population density in 2019. Notes: Reprinted with permission from Hartanto TD, Saraswati LD, Adi MS, Udiyono A. Analisis spasial persebaran kasus tuberkulosis paru di kota Semarang tahun 2018 [Spatial analysis of the distribution of cases of pulmonary tuberculosis in Semarang 2018]. Jurnal Kesehatan Masyarakat. 2019;7(4):719-727. Indonesian. Copyright 2019, Jurnal Kesehatan Masyarakat. ${ }^{31}$

(95\% CI 1.92-2.54; 56 surveys). ${ }^{45}$ Research conducted in India showed a higher increase in gender disparities in rural areas than in urban areas. From the total calculation,
$88 \%$ of respondents lived in rural areas while the other $12 \%$ lived in urban areas. ${ }^{46}$ Differences in findings could be due to the imbalanced number of male and female respondents and other characteristics in this study.

This study involved nurses as the highest number of respondents compared to other healthcare professions $(42.05 \%)$. The results of this study indicate that the risk of LTBI in various healthcare professionals is not statistically significant. These results are congruent with a study conducted in Morocco, which showed that there is no significant difference in the risk of LTBI in various healthcare professions in hospitals. The difference in the risk of LTBI incidence among healthcare workers is determined by the area where the healthcare workers work. The healthcare workers who work in the pulmonary disease service units have a fourfold increased risk of LTBI compared to the non-clinical service units. ${ }^{47}$ This is related to the characteristics of pulmonary TB, which is easily transmitted from its sufferers to others through the airway. ${ }^{48}$

The results of the study showed that $23(8.2 \%)$ respondents were smokers, and all were male. Six of them were positive for IGRA. Although smoking can reduce the immune system, it is statistically not a risk factor for LTBI $(\mathrm{OR}=2.54,95 \% \mathrm{CI}: 0.52-12.38, p=0.247)$. This result is congruent with a study conducted in 2011 in Indonesia, which showed that smoking did not appear to be strongly 
associated with $\mathrm{TB}(\mathrm{OR}=0.99,95 \%$ CI $0.76-1.31) .{ }^{49}$ Nevertheless, this finding is different from a study by AlaviNaini in 2012 in Iran that revealed a significant difference between TB and the control group concerning smoking $(p<0.0001)$. In the multivariate logistic regression test, smokers were at risk of $3.1(95 \%$ CI: 1.4-10.3) times higher for TB infection than the control group. Other factors showing significant differences between TB patients and the control were the history of smoking in the family $(\mathrm{OR}=2.8,95 \% \mathrm{CI}$ : 1.1-8.4), and smoking habit for more than ten years $(\mathrm{OR}=1.6,95 \% \mathrm{CI}: 1.2-9.8) .{ }^{50}$ Exposure to cigarette smoke that chronically occurs will decrease the percentage of dendritic cells in the lungs and change the expression of their costimulatory molecules. In addition, exposure to cigarette smoke prevents specific expansion and maximum activation of CD4 T cells and reduces the number of activated CD4 and CD8 $\mathrm{T}$ cells in response to microorganisms. As a result, the neutralization process of microorganisms will decrease, and the body's protection against viral and bacterial pathogens will also decrease, thereby increasing the prevalence of both viral and bacterial infections. ${ }^{51}$

Recently, the cases of TB have also been found in people with diabetes mellitus (DM) and HIV. This shows that the decreased immune system increases the risk of TB infection. In this study, twelve respondents who were positive for IGRA also had other diseases, including 10 person with DM and 2 person with hepatitis. The risk of current illness for LTBI is the only statistically significant risk factor among other risk factors investigated in this study ( $\mathrm{OR}=3.39,95 \% \mathrm{CI}$ : 0.99 11.62, $p=0.037$ ). The prevalence of $\mathrm{DM}$ in $\mathrm{TB}$ patients ranges from $1.9 \%$ to $45 \%$, while the median of global prevalence is 16\% (IQR 9.0-25.3\%). The prevalence of TB among DM patients ranges from $0.38 \%$ to $14 \%$, and the median of global prevalence is $4.1 \%$ (IQR $1.8-6.2 \%$ ). ${ }^{52}$ Comorbidities of TB and DM are not only found in certain regions but all regions in the world, such as Asia, Europe, and the United States. Nevertheless, Asia has the highest risk. ${ }^{53}$

Hyperglycemia interferes with the recruitment of antigen-presenting cells (APC), resulting in delays in the initiation of adaptive immunity. This situation causes a reduction of the Th1, Th2, and Th17 cell frequencies and cytokine secretion, which have a significant role in macrophage activation and the inflammatory response of tuberculosis. Impaired immune response and intracellular bacterial killing have the potential to increase the burden of bacteria, chronic inflammation, and central necrosis, which facilitates the spread of bacteria and miliary TB. ${ }^{54}$
Although not much studied, other than DM, hepatitis infection is also comorbidity to TB. Findings from a previous study by $\mathrm{Wu}$ in Taiwan showed that the incidence of active $\mathrm{TB}$ is higher in HCV infections than the controls (134.1 vs. 89.1 per 100,000 personyear; incidence rate ratio $=1.51 ; p=0.014) .{ }^{55}$ Fist-line anti-TB medications (isoniazid $=I N H$, rifampin $=$ RIF, ethambutol=EMB, pyrazinamide $=\mathrm{PZA}$ ) often produce drug-induced liver injury (DILI). The incidence of DILI was significantly higher in the HCV group (13/41 $[31.7 \%], p<0.001)$ and the $\mathrm{HBV}+\mathrm{HCV}$ group (3/4 $[75.0 \%], p=0.002)$ than in the control group $(25 / 251$ $[10.0 \%]){ }^{56}$ Patients with TB receiving Isoniazid therapy showed a five-time higher increase in hepatic enzyme (ALT/AST) levels than the controls. This result indicates the presence of liver injury in TB patients. ${ }^{57,58}$

\section{Conclusion}

The only demographic factor that acted as a risk factor for TB was the comorbidity. Other demographic factors such as age, gender, smoking habits, and length of work were not significant risk factors for LTBI among healthcare workers. Nurses were at the highest risk for LTBI compared to other healthcare professions.

\section{Suggestion}

Healthcare workers with comorbidities such as DM or hepatitis should not work in areas associated with TB patients due to their high risk of TB infection. Nurses and other healthcare workers need to apply appropriate work safety standards every time they make contact with TB patients or specimens to minimize the transmission.

\section{Acknowledgment}

The researchers would like to thank the Ministry of Research, Technology, and Higher Education (DRPM) for funding this research through the basic research grants in 2019.

\section{Disclosure}

The authors report no conflicts of interest in this study.

\section{References}

1. World Health Organisation (WHO). Global Tuberculosis Report 2019. Geneva, Switzerland: World Health Organisation; 2019.

2. Semarang Health Office. Profil Kesehatan Kota Semarang 2018 [Health Profle of Semarang 2018]. Semarang, Indonesia: Semarang Health Office; 2018.

3. World Health Organisation (WHO). Global Tuberculosis Report 2014. Geneva, Switzerland: World Health Organisation; 2014. 
4. Smith I. Mycobacterium tuberculosis: pathogenesis and molecular determinants of virulence. Clin Microbiol Rev. 2003;16(3):463-496. doi:10.1128/CMR.16.3.463-496.2003

5. Corbett EL, Muzangwa J, Chaka K, et al. Nursing and community rates of Mycobacterium tuberculosis infection among students in Harare, Zimbabwe. Clin Infect Dis. 2007;44:317-323. doi:10.1086/ 509926

6. Lubis R, Giriputro S, Handayani D, et al. High prevalence of latent tuberculosis infection among helathcare workers with history of contact with tuberculosis hospital. Respirology. 2017;22(Suppl 3):4-87.

7. Kayanja HK, Debanne S, King C, Whalen CC. Tuberculosis infection among health care workers in Kampala, Uganda. Int J Tuberc Lung Dis. 2005;9:686-688.

8. Garcia-Garcia ML, Jimenez-Corona A, Jimenez-Corona ME, et al. Factors associated with tuberculin reactivity in two general hospitals in Mexico. Infect Control Hosp Epidemiol. 2001;22:88-93. doi:10.1086/501869

9. Alonso-Echanove J, Granich RM, Laszlo A, et al. Occupational transmission of mycobacterium tuberculosis to health care workers in a university hospital in Lima, Peru. Clin Infect Dis. 2001;33:589-596. doi:10.1086/321892

10. Pai M, Gokhale K, Joshi R, et al. Mycobacterium tuberculosis infection in health care workers in rural India-comparison of a wholeblood interferon gamma assay with tuberculin skin testing. JAMA. 2005;293:2746-2750. doi:10.1001/jama.293.22.2746

11. Yanai H, Limpakarnjanarat K, Uthaivoravit W, Mastro TD, Mori T, Tappero JW. Risk of mycobacterium tuberculosis infection and disease among health care workers, Chiang Rai, Thailand. Int J Tuberc Lung Dis. 2003;7:36-45.

12. Sia IG, Wieland ML. Current concepts in the management of tuberculosis. Mayo Clin Proc. 2011;86(4):348-361. doi:10.4065/ mcp. 2010.0820

13. Hernández M, Casar C, García P, et al. Latent tuberculosis infection screening in healthcare workers in four large hospitals in Santiago. Chile Rev Chil Infectol. 2014;31(3):254-260. doi:10.4067/S071610182014000300002

14. Wei Z, Yang M, Quan B, et al. Prevalence of latent tuberculosis infection among healthcare workers in China as detected by two interferon-gamma release assays. $J$ Hosp Infect. 2013;84 (4):323-325. doi:10.1016/j.jhin.2013.04.015

15. Mirtskhulava V, Kempker R, Shields KL, et al. Prevalence and risk factors for latent tuberculosis infection among health care workers in Georgia. Int J Tuberc Lung Dis. 2008;12(5):513-519.

16. Menzies D, Joshi R, Pai M. Risk of tuberculosis infection and disease associated with work in health care settings. Int J Tuberc Lung Dis. 2007;11(6):593-605.

17. Joshi R, Reingold AL, Menzies D, Pai M, Chowdhury M. Tuberculosis among health-care workers in low- and middle-income countries: a systematic review. PLoS Med. 2006;3(12):e494. doi:10.1371/journal. pmed.0030494

18. Chu H, Shih CJ, Lee YJ, et al. Risk of tuberculosis among healthcare workers in an intermediate-burden country: a nationwide population study. J Inf Secur. 2014;69(6):525-532.

19. Zhang X, Jia H, Liu F, et al. Prevalence and risk factors for latent tuberculosis infection among health care workers in China: a cross-sectional study. PLoS One. 2013;8(6):e664.

20. Van Rie A, McCarthy K, Scott L, et al. Prevalence, risk factors and risk perception of tuberculosis infection among medical students and healthcare workers in Johannesburg. South Africa SAMJ. 2013;103 (11):853-857. doi:10.7196/samj.7092

21. Adams S, Ehrlich R, Baatjies R, et al. Incidence of occupational latent tuberculosis infection in South African healthcare workers. Eur Respir J. 2015;45(5):1364-1373. doi:10.1183/09031936.00138414

22. Simou E, Britton J, Leonardi-Bee J. Alcohol consumption and risk of tuberculosis: a systematic review and meta-analysis. Int J Tuberc Lung Dis. 2018;22(11):1277-1285. doi:10.5588/ijtld.18.0092
23. Sakar D, Jung MK, Wang HJ. Alcohol and the immune system. Alcohol Res. 2015;37(2):153-155.

24. Kubiak RW, Sarkar S, Horsburgh CR, et al. Interaction of nutritional status and diabetes on active and latent tuberculosis: across-sectional analysis. BMC Infect Dis. 2019;19(627):1-9. doi:10.1186/s12879019-4244-4

25. Luzzati R, Migliori GB, Zignol M, et al. Children under 5 years are at risk for tuberculosis after occasional contact with highly contagious patients: outbreak from a smear-positive healthcare worker. Eur Respir J. 2017;50:1701414. doi:10.1183/13993003.01414-2017

26. The Indonesian Society of Respirology. Pedoman Tatalaksana Infeksi $T B$ Laten [Guidelines for the Management of Latent TB Infection]. Jakarta, Indonesia: Badan Penerbit FK UI; 2016.

27. Wolters OW, Leinbach TR, Legge JD, McDivitt JF, Adam AW, Mohamad GS. Indonesia: population density. In: Encyclopaedia Britannica. Chicago, IL: Encyclopædia Britannica, Inc. ; 2020.

28. World Health Organisation (WHO). Tuberculosis Country Profiles 2018. Geneva, Switzerland: World Health Organisation; 2018.

29. Aryanti Y, Suhartono S, Dewanti NA. Analisis Sebaran Kasus TB Paru BTA Positif di Kota Semarang Tahun 2018 berdasarkan Suhu Udara [Analysis of the distribution of pulmonary TB cases in Semarang in 2018 based on air temperature]. Jurnal Kesehatan Masyarakat. 2019;7(4):273-278.

30. Gelaw YA, Yu W, Magalhaes RJS, Assefa Y, Williams G. Effect of temperature and altitude difference on tuberculosis notification: a systematic review. $J$ Glob Infect Dis. 2019;11(2):63-68. doi:10.4103/jgid.jgid_95_18

31. Hartanto TD, Saraswati LD, Adi MS, Udiyono A. Analisis spasial persebaran kasus tuberkulosis paru di kota Semarang tahun 2018 [Spatial analysis of the distribution of cases of pulmonary tuberculosis in Semarang 2018]. Jurnal Kesehatan Masyarakat. 2019;7 (4):719-727.

32. Almufty AB, Abdulrahman IS, Merza MA. Latent tuberculosis infection among healthcare workers in Duhok Province: from screening to prophylactic treatment. Trop Med Infect Dis. 2019;4(85):1-11.

33. Al-Lami F, Armean P, Al-Ameri AH. Prevalence of latent TB infection among healthcare workers in three main TB health facilities, Baghdad, Iraq, 2013. J Fac Med. 2014;56:339-342.

34. Ratnawati BE, Intani CN, Handayani H, Nurwidya F. Comparison of tuberculin skin test and interferon-gamma release assay in the diagnosis of latent tuberculosis infection among Indonesian health-care workers. J Nat Sc Biol Med. 2019;10:53-59. doi:10.4103/jnsbm. JNSBM_67_18

35. World Health Organization (WHO). Giudelines on the Management of Latent Tuberculosis Infection. Geneva, Switzerland: World Health Organisation; 2015.

36. Doan TN, Eisen DP, Rose MT, Slack A, Stearnes G, McBryde ES. Interferon-gamma release assay for the diagnosis of latent tuberculosis infection: a latent-class analysis. PLoS One. 2017;12(11): e0188631. doi:10.1371/journal.pone.0188631

37. Klautau GB, da Mota NVF, Salles MJC, Burattini MN, Rodrigues DS. Interferon- $\gamma$ release assay as a sensitive diagnostic tool of latent tuberculosis infection in patients with HIV: a crosssectional study. BMC Infect Dis. 2018;18(585):1-8. doi:10.1186/s12879-018-3508-8

38. Simon AK, Hollander GA, McMichael A. Evolution of the immune system in humans from infancy to old age. Proc $R$ Soc. 2015;282:20143085. doi:10.1098/rspb.2014.3085

39. Li M, Yao D, Zeng $X$, et al. Age related human $\mathrm{T}$ cell subset evolution and senescence. Immun Ageing. 2019;16(24):1-7. doi:10.1186/s12979-019-0165-8

40. Schablon A, Harling M, Diel R, Nienhaus A. Risk of latent TB infection in individuals employed in the healthcare sector in Germany: a multicentre prevalence study. BMC Infect Dis. 2010;10 (107):1-10. doi:10.1186/1471-2334-10-107 
41. Christopher DJ, Daley P, Armstrong L, et al. Tuberculosis infection among young nursing trainees in South India. PLoS One. 2010;5: e10408. doi:10.1371/journal.pone.0010408

42. Davison G, Kehaya C, Jones AW. Nutritional and physical activity interventions to improve immunity. Am J Lifestyle Med. 2016;10 (3):152-169. doi:10.1177/1559827614557773

43. Barak Y. The immune system and happiness. Autoimmun Rev. 2006;5 (8):523-527. doi:10.1016/j.autrev.2006.02.010

44. Wang X, He T, Geng M, et al. Prevalence of and risk factors for tuberculosis among healthcare workers in Chinese tuberculosis facilities. Infect Dis Poverty. 2018;7(26):1-11. doi:10.1186/s40249-018-0407-6

45. Horton KC, MacPherson P, Houben RMGJ, White RG, Corbett EL. Sex differences in tuberculosis burden and notifications in low- and middle-income countries: a systematic review and meta-analysis. PLoS Med. 2016;13(9):e1002119. doi:10.1371/journal.pmed.1002119

46. Sharma PP, Kumar A, Singh P. A study of gender differentials in the prevalence of tuberculosis based on NFHS-2 and NFHS-3 data. Indian J Community Med. 2010;35(2):230-237. doi:10.4103/0970-0218.66869

47. Sabri A, Quistrebert J, Naji Amrani H, et al. Prevalence and risk factors for latent tuberculosis infection among healthcare workers in Morocco. PLoS One. 2019;14(8):e0221081. doi:10.1371/journal.pone.0221081

48. Nardell EA. Transmission and institutional infection control of tuberculosis. Cold Spring Harb Perspect Med. 2016;6:a018192. doi:10.1101/cshperspect.a018192

49. Sahiratmadja E, Nagelkerke N. Smoking habit as a risk factor in tuberculosis: a case-control study. Univ Med. 2011;30:189-196.

50. Alavi-Naini R, Sharifi-Mood B, Metanat M. Association between tuberculosis and smoking. Int J High Risk Behav Addict. 2012;1 (2):71-74. doi:10.5812/ijhrba
51. Robbins CS, Dawe DE, Goncharova SI, et al. Cigarette smoke decreases pulmonary dendritic cells and impacts antiviral immune responsiveness. Am J Respir Cell Mol Biol. 2004;30:202-211. doi:10.1165/rcmb.2003-0259OC

52. Workneh MH, Bjune GA, Yimer SA, Wilkinson KA. Prevalence and associated factors of tuberculosis and diabetes mellitus comorbidity: a systematic review. PLoS One. 2017;12(4):e0175925. doi:10.1371/ journal.pone. 0175925

53. Al-Rifai RH, Pearson F, Critchley JA, Abu-Raddad LJ. Association between diabetes mellitus and active tuberculosis: a systematic review and meta-analysis. PLoS One. 2017;12(11):e0187967. doi:10.1371/journal.pone.0187967

54. Ayelign B, Negash M, Genetu M, Wondmagegn T, Shibabaw T. Immunological impacts of diabetes on the susceptibility of mycobacterium tuberculosis. J Immunol Res. 2019;2019:1-8.

55. Wu P, Lin Y, Hsieh K, Chuang H, Sheu C. Hepatitis C virus infection is associated with an increased risk of active tuberculosis Disease A Nationwide Population-Based Study. Medicine (Baltimore). 2015;94(33):e1328. doi:10.1097/MD.0000000000001328

56. Kim WS, Lee SS, Lee CM, et al. Hepatitis C and not hepatitis B virus is a risk factor for anti-tuberculosis drug induced liver injury. $B M C$ Infecti Dis. 2016;16(50):1-7.

57. Tweed CD, Wills GH, Crook AM, et al. Liver toxicity associated with tuberculosis chemotherapy in the REMoxTB study. BMC Med. 2018;16(46):1-10. doi:10.1186/s12916-018-1033-7

58. McGill MR. The past and present of serum aminotransferases and the future of liver injury biomarkers. EXCLI J. 2016;15:817-828. doi:10.17179/excli2016-800
Journal of Multidisciplinary Healthcare

\section{Publish your work in this journal}

The Journal of Multidisciplinary Healthcare is an international, peerreviewed open-access journal that aims to represent and publish research in healthcare areas delivered by practitioners of different disciplines. This includes studies and reviews conducted by multidisciplinary teams as well as research which evaluates the results or conduct of such teams or healthcare processes in general. The journal

\section{Dovepress}

covers a very wide range of areas and welcomes submissions from practitioners at all levels, from all over the world. The manuscript management system is completely online and includes a very quick and fair peer-review system. Visit http://www.dovepress.com/testimonials. php to read real quotes from published authors. 